AUTORA:

Érika Goulart Veloso Ferrera

ORIENTADORA:

\title{
Avaliação da qualidade de vida e aspectos psicológicos em pacientes com doença trofoblástica gestacional
}

Profa. Dra. Marilza VierRa Cunha Rudge

CO-ORIENTADORA:

Profa. Dra. IZILDINHa Maestá

\author{
Assessment of quality of life and psychological aspects in patients with \\ gestational trophoblastic disease
}

Resumo de tese

Palavras-chave

Doença trofoblástica gestacional

Qualidade de vida

Aspectos psicológicos

Keywords

Gestational trophoblastic disease

Quality of life

Psychological aspects

Dissertação apresentada ao Programa de Pós-graduação em Ginecologia, Obstetrícia e Mastologia da Faculdade de Medicina de Botucatu da Universidade Estadual Paulista "Júlio de Mesquita Filho"- UNESP - Área de Concentração: Obstetrícia, para obtenção do título de Mestre, em 3 de outubro de 2008.

OBJETIVO: avaliar qualidade de vida e aspectos psicológicos em pacientes com doença trofoblástica gestacional (DTG). MÉTODOS: estudo transversal, no qual foram incluídas 54 pacientes tratadas no Centro de Doenças Trofoblásticas de Botucatu (SP). Questionários validados foram usados para avaliar qualidade de vida (QV) (WHOQOL-bref), sintomas de depressão (Inventário de Depressão de Beck-IDB) e ansiedade (Inventário de Ansiedade Traço-Estado-IDATE). RESULTADOS: a maioria das pacientes considerou a QV geral como boa $(44,4 \%)$, e estavam satisfeitas com seu estado de saúde $(42,5 \%)$. Dos escores médios de QV, o mais baixo foi para saúde psicológica $(53,8 \pm 21,4)$ e o mais alto para relações

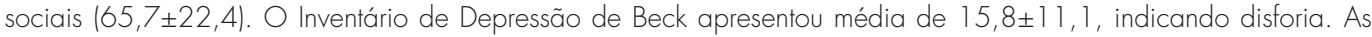

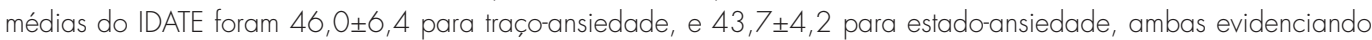
média-alta ansiedade. Entre pacientes que tinham emprego, a média do domínio meio ambiente foi significativamente mais alta $(p=0,02)$. A presença de filhos antes da doença resultou em menor média nos domínios físico $(p=0,04)$ e meio ambiente $(p=0,04)$. As pacientes que desejavam ter filhos apresentaram médias significativamente maiores para os domínios físico ( $p=0,004)$, psicológico $(p=0,02)$ e meio ambiente $(p=0,003)$. O tratamento quimioterápico não teve influência significativa sobre a qualidade de vida (p>0,05). CONCLUSÃO: este estudo evidenciou o impacto psicológico sobre pacientes com DTG, sugerindo que centros especializados devem dispor de intervenções psicológicas durante o tratamento e seguimento de pacientes com DTG, realçando a importância de uma abordagem multidisciplinar.

AUTORA:

Thais de Olivera Gozzo

ORIENTADORA:

\section{Toxicidade ao tratamento quimioterápico em mulheres com câncer de mama}

Profa. Dra. Ana Maria de Almeida

\author{
Toxicity to chemotherapy treatment in women with breast cancer
}

Resumo de tese

Palavras-chave

Enfermagem

Neoplasias mamárias

Quimioterapia

Efeitos adversos

Kewwords

Breast neoplasms Chemotherapy

Adverse effects
Tese apresentada ao Programa Interunidades de Doutoramento em Enfermagem da Escola de Enfermagem e Escola de Enfermagem de Ribeirão Preto da Universidade de São Paulo (USP) para obtenção do título de Doutor em Enfermagem, em 18 de junho de 2008.

OBJETIVO: analisar a ocorrência de toxicidade hematológica induzida por drogas utilizadas no protocolo de quimioterapia neoadjuvante e adjuvante entre mulheres com câncer de mama. MÉTODO: estudo retrospectivo, com revisão de 72 prontuários de mulheres submetidas ao tratamento quimioterápico neoadjuvante com epirrubicina e docetaxel e epirrubicina e ciclofosfamida no adjuvante. Os prontuários revisados foram de mulheres na faixa etária de 30 a 60 anos, que receberam o tratamento quimioterápico entre os anos de 2003 e 2006. RESULTADOS: a média de idade das participantes foi de 47,8 anos. As participantes foram divididas em dois grupos, um com 31 mulheres que apresentaram neutropenia e o outro com 41 que não apresentaram. Observou-se que 43\% das mulheres apresentaram neutropenia; analisadas entre os ciclos de quimioterapia, foram estatisticamente significantes para os ciclos dois e três da neoadjuvância com valor de p de 0,0016 e 0,0009, respectivamente; para os ciclos dois e três da adjuvância com valor de p de 0,00 14 e 0,0030, respectivamente; para o final do tratamento neoadjuvante, anterior ao tratamento cirúrgico com valor de $p=<0,0001$ e, para o final do tratamento adjuvante, com valor de $\mathrm{p}=<0,0004$. Quanto à ocorrência de anemia, esta não esteve relacionada à neutropenia, entretanto, observou-se uma queda nos valores de hemoglobina durante a neoadjuvância, com ligeira recuperação no período de adjuvância; não houve recuperação aos valores médios anteriores ao tratamento quimioterápico. A redução da dose foi utilizada para seis mulheres em decorrência da toxicidade hematológica. CONCLUSÃO: por meio dos resultados deste estudo, demonstra-se a necessidade de elaboração e implementação de protocolos de cuidados de enfermagem para pacientes oncológicos com a finalidade de avaliação dos eventos adversos e manejo mais adequado dos mesmos. 